\title{
PENGARUH MOTIVASI BELAJAR TERHADAP HASIL BELAJAR SISWA DALAM PEMBELAJARAN DARING
}

\author{
Nurfaliza $^{1^{*}}$, Nur Eka Kusuma Hindrasti ${ }^{1}$ \\ ${ }^{1}$ Pendidikan Biologi, Universitas Maritim Raja Ali Haji \\ *nurfaliza49@gmail.com
}

Received: January $28^{\text {th }}, 2022$

Revised: March $18^{\text {th }}, 2021$

Accepted: March $19^{\text {th }}, 2021$

\begin{abstract}
Online learning leaves behind as problems that make students' learning spirit decrease. Giving encouragement and motive to students is expected to be able to adjust even though the situation is difficult to compromise. This is what happened to one of the students of SMP Negeri 3 Bintan Timur who felt that during online learning his learning achievements improved and learning motivation was a factor that influenced the success gained. This study is a case study with qualitative approach that seeks to explore the motives of the subject in improving learning outcomes, especially in online learning. Researchers collected data using interview techniques directly to subjects and parents as well as questionnaires through google forms to teachers and friends of the subject, with a total of two people each. Furthermore, data processing is done by analyzing students' problems, then seeking information from sources or people closest to the subject and finally finding the motives of the subject in improving learning achievement. The results showed that the provision of learning motivation can improve the learning outcomes of the subject, this is proven by the subject successfully becoming an outstanding student in the classroom. The purpose of this research is to explore the motivation of learning the subject and know the role of parents, teachers and friends in providing learning motivation. With this research can contribute to students, teachers and parents that the motivation of learning is very necessary to grow in order to strengthen the desired goals can be achieved.
\end{abstract}

Keywords: eagar to learn; learning motivation; online learning.

\section{PENDAHULUAN}

Saat ini kita masih hidup berdampingan dengan wabah Covid-19. Pemerintah mengambil kebijakan yang mengharuskan masyarakat Indonesia belajar, bekerja dan beraktifitas di dalam rumah. Terlepas dari berbagai kebijakan yang diambil pemerintah, ternyata memiliki dampak yang signifikan khususnya dalam bidang pendidikan. Pembelajaran yang semulanya luring (tatap muka) kini telah beralih menjadi daring (E-learning). Berbagai masalahpun mulai muncul 
dikarenakan kurangnya persiapan warga sekolah dalam menghadapi perubahan drastis tersebut. Permasalahan daring diantaranya sulitnya mengakses jaringanya internet, smartphone dan komunikasi penghubung lainnya yang masih terbatas, kouta internet yang mahal (Putra, Witri, \& Sari, 2020), penguasaan IPTEK belum merata baik guru maupun siswa, kaget dan belum siap dengan kegiatan mengajar dengan metode pembelajaran jarak jauh serta orang tua mengalami kesulitan dalam mendampingi anak saat belajar di rumah.

Hal inilah yang dialami oleh seorang siswa SMP Negeri 3 Bintan Timur. Dalam wawancara yang dilakukan oleh peneliti, pada saat awal pembelajaran daring mengakui bahwa sulit memahami materi yang diajarkan oleh guru. Kondisi ini membuat semangat belajar siswa menurun karena berbagai permasalahan seperti kouta internet dan penugasan yang memberatkan. Selain itu, kurangnya penjelasan terhadap materi pembelajaran yang disampaikan oleh guru juga membuat siswa jenuh ditambah lagi pemberian tugas yang berlebihan dan tenggat waktu yang diberikan terbatas. Kondisi ini juga memicu rendahnya partisipasi siswa selama pembelajaran daring. Di sisi lain, subjek mengatakan bahwa karena ikut-ikutan teman, siswa tersebut kecanduan bermain game online yang menyebabkan lalai dalam mengerjakan tugas sehingga berdampak buruk pada hasil belajar. Melihat peristiwa tersebut, semua pihak harus berperan dalam meningkatkan mutu pembelajaran termasuk orang tua. Peran orang tua sangat dominan dalam hal ini karena anak lebih banyak menghabiskan waktu belajar di rumah. Selama pembelajaran daring, pentingnya menumbuhkan semangat belajar membuat orang tua menyadari bahwa anak harus memiliki keinginan kuat sehingga mengubah pola pikirnya bahwa belajar sangat penting bagi kehidupan.

Perkembangan belajar siswa dikatakan telah mencapai secara optimal apabila mampu memperoleh pendidikan dan prestasi yang sesuai dengan kemampuan, minat, bakat dan motivasi belajar yang dimilikinya. Segala sesuatu usaha yang dilakukan siswa karena adanya motivasi (Lestari, Syahrilfuddin, Putra, \& Hermita, 2019; Rokhayati, Tanuredja, \& Jazuli, 2020; Yuliana, Putra, \& Antosa, 2020;. Jika motivasi belajar baik dampak baiknya akan melahirkan hasil belajar 
yang baik. Ini artinya, siswa yang memiliki motivasi belajar yang tinggi dapat menunjang prestasi belajar yang tinggi pula. Hal ini dibuktikan dengan pendapat menurut Sardiman (2008: 73) menyatakan bahwa "motivasi merupakan daya penggerak dari dalam untuk melakukan kegaiatan untuk mencapai tujuan". Kasus inilah yang dirasakan oleh subjek penelitian, selama pembelajaran daring prestasinya dibidang akedemik mulai meningkat. la menuturkan bahwa hal itu terjadi karena ada beberapa faktor yang membuatnya semangat dalam belajar. Dan salah satu pendorong meningkatnya hasil belajar subjek adalah motivasi.

Motivasi belajar merupakan semua daya penggerak yang mendorong siswa bersungguh-sungguh dalam belajar. Motivasi belajar juga berarti motif internal dan eksternal siswa dalam proses perubahan tingkah laku yang didukung dengan beberapa indikator seperti (a) memiliki hasrat dan keinginan untuk berhasil; (b) memiliki kebutuhan terhadap belajar; (c) memiliki harapan dan cita-cita yang tinggi; (d) memiliki apresiasi belajar; (e) adanya pembelajaran yang menarik dan; (f) lingkungan belajar yang kondusif, sehingga siswa dapat belajar dengan baik dan nyaman (Yarangga: 2016).

Dalam belajar, motivasi sangatlah penting karena dapat menjadi tolak ukur keberhasilan dan kegagalan belajar siswa. Belajar tanpa adanya motivasi dirasa akan sulit berhasil, sebab seseorang tidak memiliki motivasi belajar tidak akan dapat melakukan kegiatan belajar. Oleh karena itu, penguatan motivasi belajar siswa harus dilakukan terus-menerus. Dalam pembelajaran, motivasi dapat menjadi tenaga pendorong siswa untuk memaksimalkan kemampuan dan potensi yang dimilikinya untuk mewujudkan tujuan belajar.

Penelitian ini bertujuan mendalami motivasi belajar salah seorang siswa di SMP Negeri Bintan Timur yang semula semangat belajar menurun menjadi meningkat bahkan menjadi siswa berprestasi di sekolah. Manfaat dari penelitian adalah untuk membangkitkan semangat belajar siswa berdasarkan studi kasus yang diangkat penulis sehingga nantinya dapat dijadikan acuan dasar dalam membangun pribadi siswa berpartisipasi dan aktif dalam pembelajaran. Maka dari 
itu, urgensi motivasi belajar untuk meningkatkan hasil belajar yang baik sangat dibutuhkan agar tujuan yang diharapkan dapat teraktualisasikan.

\section{METODE PENELITIAN}

Metode yang digunakan peneliti yaitu studi kasus dengan pendekatan kualitatif. Penelitian studi kasus merupakan seperangkat kegiatan ilmiah yang tersusun secara sistematis dalam mendalami suatu hal baik orang, lembaga, peristiwa, program atau organisasi untuk mendapatkan pembelajaran yang bermanfaat (Rahardjo: 2017). Masalah dalam metode harus unik, yang berarti hanya terjadi pada situs tertentu dan lokus tertentu. Adapun subjek penelitian yakni siswa di SMP Negeri 3 Bintan Timur berinisial AL yang memiliki hasil belajar yang meningkat saat pembelajaran daring serta orang tua, teman dan guru sebagai subjek pendukung yang mempengaruhi motivasi belajar AL.

Teknik pengumpul data yang digunakan adalah wawancara secara langsung kepada siswa dengan pedoman wawancara yang digunakan kepada subjek membahas tentang mengapa dan bagaimana menumbuhkan semangat belajar selama pandemi serta laporan hasil belajar sebagai data penguat. Selain itu, untuk mengetahui bagaimana peran dan karakter subjek penelitian melalui informan seperti orang tua, guru dan teman subjek. Untuk pedoman wawancara kepada orang dilakukan secara langsung. Sedangkan guru dan teman berupa kuesioner melalui google form. Dari hasil wawancara tersebut, penulis kemudian menganalisis data menjadi temuan konseptual terhadap keberhasilan subjek dalam belajar yang dipengaruhi oleh motivasi dari orang tua, guru dan teman.

\section{HASIL DAN PEMBAHASAN}

\section{Hasil Penelitian}

Adapun hasil wawancara yang terkumpul dari subjek dan informan, yaitu:

Wawancara dengan guru 
Menurut penjelasan dari guru, subjek kasus merupakan anak selalu tepat waktu mengerjakan tugas diberikan, namun dari segi pemahaman AL termasuk biasa saja. AL termasuk siswa yang pendiam dan sukar diajak berbicara kepada orang yang belum kenal dekat. Guru menuturkan bahwa subjek memiliki perwatakan yang patuh dan ketika disampaikan tentang kesalahan dalam pembelajaran AL senantiasa mendengarkan dengan baik kemudian menasehati subjek agar bergaul dengan bijaksana karena AL mudah terpengaruh dari perilaku teman. Sehingga selama pembelajaran yang notabenenya jarang bertemu dengan teman, AL lebih fokus dalam belajar. Terakhir, guru merasa bahwa dari belajar AL mengalami peningkatan yang dibuktikan dengan AL mendapat peringkat 3 di kelas.

Wawancara dengan teman

Berdasarkan penjelasan dari beberapa teman, subjek termasuk anak yang introvert dan hanya dekat dengan orang tertentu saja. Dalam pembelajaran AL tidak canggung mengajari bila ada teman yang tidak paham materi. Teman-teman juga mengakui bahwa AL selama pembelajaran lebih rajin dan cepat dalam mengerjakan tugas yang diberikan.

Wawancara dengan orang tua

Menurut keterangan orang tua, subjek termasuk anak yang penurut dan mengerti dengan keadaan keluarga. AL juga suka rajin membantu kedua orang tuanya. Dalam belajar, AL sering bertanya khususnya kepada keluarga apabila mengalami kesulitan belajar. Diakui juga bahwa keluarga akan memberikan hadiah apabila AL mampu meraih peringkat kelas. Orang tua AL menyatakan bahwa setelah diberikan motivasi tersebut semangat belajar AL menjadi meningkat.

Wawancara dengan subjek penelitian

Berdasarkan keterangan, subjek sama seperti siswa lainnya. AL mengatakan bahwa tidak ada yang terlalu istimewa ataupun kelebihan darinya khususnya dalam belajar. Hanya saja selama pembelajaran daring partisipasinya mulai meningkat. Hal ini juga didukung dengan sarana belajar dan akses internet yang 
memadai Diakui ternyata $\mathrm{AL}$ selalu mengerjakan tugas tepat waktu dan kehadirannya dalam pembelajaran nyaris tak pernah nihil. Subjek juga menyadari bahwa keadaan tidak dapat menyulutkan semangatnya dalam belajar. Hal ini subjek buktikan dengan perbandingan laporan hasil belajarnya mulai dari kelas VII hingga kelas IX semester ini yang dinyatakan dalam diagram berikut:

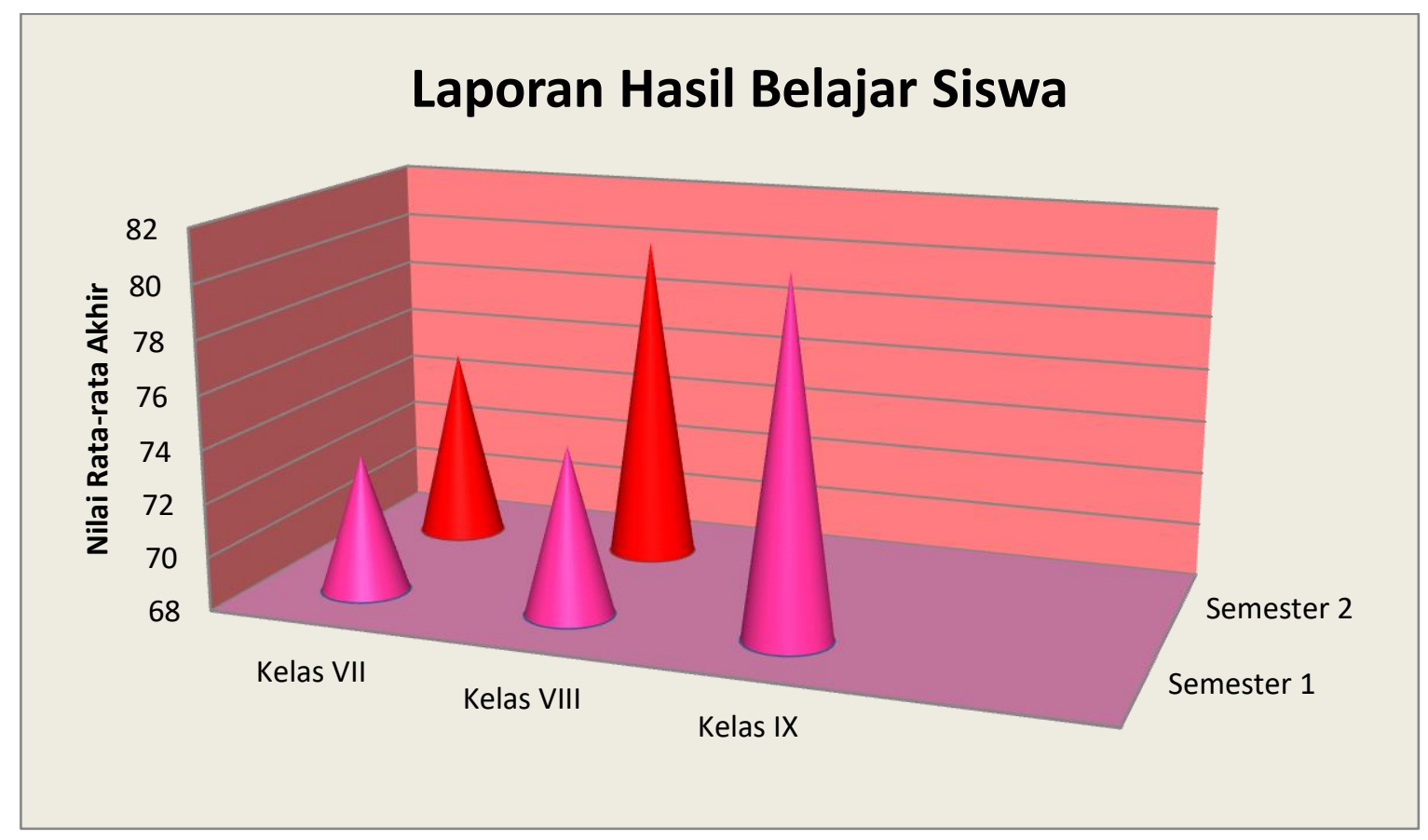

Dari laporan tersebut menunjukkan pada kelas VII rata nilai adalah 73,2 dan 75,2. Kemudian pada kelas VII mengalami penurunan di semester awal yakni 74,9 dan di semester akhir naik kembali menjadi 80,2. Selanjutnya pada saat pembelajaran daring tepatnya semester 1 kelas IX rata-rata nilai subjek meningkat yakni 81,1 dan mendapatkan juara kelas.

\section{Pembahasan Penelitian}

Berdasarkan wawancara dan temuan yang dilakukan, terlihat bahwa subjek sangat antusias dalam pembelajaran. Dukungan dari orang tua, guru dan teman ikut berperan dalam memberikan stimulus dan rangsangan terhadap motivasi belajar. Motivasi belajar (Sardiman, 2014: 75) bersifat nonintelektual berdasarkan faktor psikis siswa. Siswa yang mempunyai motivasi, akan memiliki banyak energi dalam melakukan pembelajaran. Hasil belajar pun akan optimal apabila motivasi 
tepat sasaran. Adapun motivasi belajar yang subjek alami dapat dilihat melalui motivasi intrinsik dan motivasi ekstrinsik.

1. Motivasi intrinsik

Motivasi intrinsik merupakan motivasi yang fungsi dan aktif tanpa rangsangan dari luar karena individu tersebut sudah memiliki dorongan dan tujuan dari dalam dirinya sendiri (Sardiman: 2014: 89). Motivasi intrinsik muncul apabila situasi belajar bertemu dengan kebutuhan dan tujuan siswa inheren untuk menguasai pembelajaran tersebut. Siswa belajar semata-mata termotivasi untuk menguatkan pemahaman dan nilai-nilai yang terkandung dalam pelajaran, bukan karena keinginan lain seperti hadiah, pujian atau nilai yang tinggi. Jadi motivasi intrinsik timbul berdasarkan tujuan murni bukan hanya atribut dan seremonial.

Berdasarkan hasil penelitian, terlihat bahwa subjek memiliki motivasi belajar yang tinggi salah satunya dari motivasi intrinsik. Motivasi subjek dapat dirasakan selama proses pembelajaran berlangsung, subjek tekun dalam mengerjakan tugas-tugas karena merasa butuh akan belajar tanpa mengharapkan pujian. Dalam hal ini, siswa yang memiliki motivasi intrinsik dapat menunjukkan aktifitas yang lebih tinggi dan mencapai kepuasan ketika mampu memecahkan permasalahan khususnya mengerjakan tugas selama belajar dengan baik.

2. Motivasi ekstrinsik

Motivasi ekstrinsik antonim dari motivasi intrinsik atau motivasi yang muncul akibat rangsangan dari luar individu. Motivasi ekstrinsik terjadi apabila siswa mampu menempatkan tujuannya diluar faktor-faktor situasi belajar. Banyak cara yang dapat menumbuhkan motivasi ekstrinsik. Adapun beberapa cara dalam menumbuhkan motivasi tersebut diantaranya:

1) Nilai

Nilai merupakan proses pengumpulan dan pengolahan informasi sebagai tolak ukur pencapaian hasil belajar siswa. Dalam hal ini penilaian dapat menggunakan angka sebagai simbol. Semakin banyak siswa belajar, maka nilai yang dihasilkan akan semakin baik. Selama proses pembelajaran 
guru akan memberikan berbagai latihan dan ujian kepada siswa untuk menilai seberapa paham siswa terhadap materi pelajaran. Pemberian nilai yang sesuai dapat menggerakkan motivasi belajar siswa karena menyadari berbagai kekurangan untuk ditingkatkan lagi ke depannya.

Hal inilah yang dapat dilihat dari subjek penelitian. Karena menyadari bahwa hasil belajarnya di kelas VII dan VIII cukup rendah maka perlu usaha untuk memperbaiki nilai tersebut menjadi lebih baik. Perilaku ini merupakan salah motif subjek untuk meningkatkan hasil belajarnya.

2) Hadiah

Hadiah juga dapat dikatakan sebagai stimulus atas motif siswa dalam belajar. Hadiah juga diberikan pada anak apabila mampu menunjukkan hasil belajar yang baik. Hadiah merupakan pemantik semangat belajar anak sehingga lebih terpacu giat dalam belajar. Pemberian hadiah sematamata hanya sebagai penyemangat agar siswa semangat dalam belajar. Karena pada dasarnya, dalam mengerjakan sesuatu haruslah ikhlas tanpa mengharapkan imbalan. Hadiah berfungsi sebagai insentif atau membesarkan giatnya usaha anak untuk memperbaiki dan mempertinggi prestasi, maka pemberian hadiah diawal dirasa penting untuk meningkatkan motivasi belajar siswa.

Dalam hal ini, orang tua subjek berjanji diawal masuk persekolahan bahwa apabila subjek mampu menjadi juara kelas maka orang tua akan memberikan handphone baru. Terbukti bahwa pada kelas IX semester 1 ini subjek mampu menjadi juara kelas. Ini berarti, stimulus berupa hadiah dapat menambah semangat siswa dalam belajar.

3) Pujian

Pujian dapat memupuk kepercayaan diri siswa agar lebih giat lagi dalam belajar. Pemaknaan pujian yang baik dapat membuat suasana belajar menjadi menyenangkan dan penuh gairah belajar. Kegiatan ini yang sering dilakukan oleh teman subjek. Karena subjek selalu membantu temantemannya dalam memahami materi yang kurang dimengerti maka menimbulkan rasa solidaritas yang kuat. Hal ini sangat penting, karena 
subjek menyadari bahwa pengetahuan itu harus dibagi dalam konteks yang benar sehingga kebermanfaatan pembelajaran dapat dirasakan.

\section{SIMPULAN}

Dari penjabaran di atas dapat tarik sebuah kesimpulan bahwa pemberian motivasi belajar sangat penting dan berpengaruh khususnya dalam menunjang hasil belajar. Subjek penelitian merupakan siswa yang terbukti mampu mengambil hikmah dari setiap motif-motif yang didapatkan sehingga menimbulkan motivasi belajar baik secara intrinsik maupun ekstrinsik. Motivasi belajar merupakan bahan bakar yang mendorong siswa untuk meraih tujuan yang diingingkan sehingga dapat meningkatkan siswa aktif dan berprestasi di kelas. Penulis berharap, dengan adanya kajian seperti ini dapat membantu pihak-pihak terkait dalam menumbuhkan semangat belajar anak walaupun pandemi. Untuk penelitian ke depannya, penulis berharap kajian ini dapat terus digali guna menjadi evaluasi yang menyeluruh bagi semua kalangan.

\section{DAFTAR PUSTAK}

Emda, A. (2017). Kedudukan Motivasi Belajar Siswa dalam Pembelajaran. Jurnal Lantanida, $\quad$ 5(2), 93-196. https://www.jurnal.arraniry.ac.id/index.php/lantanida/article/view/2838

Kompri. (2015). Motivasi Pembelajaran Perspektif Guru dan Siswa. Bandung: PT Remaja Rosdakarya.

Lestari, S., Syahrilfuddin, S., Putra, Z. H., \& Hermita, N. (2019). The effect of realistic mathematic approach on students' learning motivation. Journal of Teaching and Learning in Elementary Education, 2(2), 145-156.

Makrifat. (2012). Pengaruh Motivasi Belajar Terhadap Prestasi Siswa Pada Bidang Studi PAI di SMA-IT Wahdah Islamiyah Makassar. Disertasi, dipublikasikan. Universitas Islam Negeri Alauddin Makassar.

Oemar. H. (2001). Proses Belajar Mengajar. Jakarta. PT Bumi Aksara. 
Purwanto. (2014). Evaluasi Hasil Belajar. Yogyakarta. Pustaka Belajar.

Putra, Z. H., Witri, G., \& Sari, I. K. (2020). Prospective elementary teachers' perspectives on online mathematics learning during coronavirus outbreak. In Journal of Physics: Conference Series (Vol. 1655, No. 1, p. 012057). IOP Publishing.

Rahardjo, M. (2017). Studi Kasus dalam Penelitian Kualitatif; Konsep dan Prosedurnya. Jurnal Penelitian, 2(5), 139-196. http://repository.uinmalang.ac.id/1104/

Rokhayati, T., Tanuredja, T., \& Jazuli, A. (2020). Pengaruh Permainan Crossword Puzzle terhadap Motivasi dan Hasil Belajar Peserta Didik SD IT Harapan Umat Purbalingga. Tunjuk Ajar: Jurnal Penelitian IImu Pendidikan, 3(1), 6576.

Sadirman. (2014). Interaksi dan Motivasi Belajar Mengajar. Jakarta; PT. Raja Grafindo Persada.

Sardirman, A.M. (2008). Interaksi dan Motivasi Belajar Mengajar. Jakarta : Rajawali Pers.

Sudjana. (2016). Penilaian Hasil Proses Belajar Mengajar. Bandung. Rosdakarya.

Yarangga, F. S. (2016). Hubungan Motivasi Belajar Dengan Hasil Belajar IPS Siswa Kelas III Gugus Wijaya Kusuma Ngaliyan Semarang. Disertasi, dipublikasikan. Universitas Negeri Semarang.

Yuliana, Y., Putra, M. J. A., \& Antosa, Z. (2020). Faktor-Faktir Yang Mempengaruhi Motivasi Siswa Sekolah Dasar Dalam Mengikuti Aktivitas Pramuka Penggalang. Tunjuk Ajar: Jurnal Penelitian IImu Pendidikan, 3(2), 210-226. 


\section{LAMPIRAN}

Pedoman wawancara Subjek

\begin{tabular}{|l|l|}
\hline No. & \multicolumn{1}{|c|}{ Pertanyaan } \\
\hline 1. & Apakah kamu menyukai pembelajaran daring? Mengapa? \\
\hline 2. & Apa kendala yang kamu rasakan saat belajar khususnya selama pandemi? \\
\hline 3. & Bagaimana guru menyajikan materi selama pembelajaran jarak jauh? \\
\hline 4. & $\begin{array}{l}\text { Apakah kamu mengerti selama pembelajaran daring berlangsung? } \\
\text { Mengapa? }\end{array}$ \\
\hline 5. & Apa yang membuat kamu semangat belajar? \\
\hline 6. & Apakah kamu memiliki target selama belajar? \\
\hline 7. & Mengapa hadiah dapat menumbuhkan semangat belajarmu? \\
\hline 8. & Bagaimana sikap orang tuamu dalam membimbing kamu belajar? \\
\hline 9. & Bagaimana perasaanmu ketika berhasil menjadi juara kelas? \\
\hline 10. & Apa harapanmu ke depannya? \\
\hline
\end{tabular}

Pedoman wawancara Guru

\begin{tabular}{|l|l|}
\hline No. & \multicolumn{1}{|c|}{ Pertanyaan } \\
\hline 1. & $\begin{array}{l}\text { Apakah AL termasuk siswa yang aktif dan tepat waktu dalam mengerjakan } \\
\text { tugas selama belajar jarak jauh? }\end{array}$ \\
\hline 2. & $\begin{array}{l}\text { Apakah AL termasuk siswa yang cepat dalam memahami materi yang } \\
\text { disajikan? }\end{array}$ \\
\hline 3. & Dapatkah Bapak mendeskripsikan AL dalam belajar? \\
\hline 4. & Kelebihan yang dimiliki AL dalam belajar? \\
\hline 5. & Kekurangan yang AL miliki dalam belajar? \\
\hline
\end{tabular}


Pedoman wawancara Orang tua

\begin{tabular}{|l|l|}
\hline No. & \multicolumn{1}{|c|}{ Pertanyaan } \\
\hline 1. & Apakah AL termasuk anak yang semangat dalam belajar? \\
\hline 2. & Bisakah Bapak/lbu ceritakan karakter dan sikap AL sebagai anak? \\
\hline 3. & Ketika AL kesulitan dalam belajar, apakah subjek meminta bantuan? \\
\hline 4. & Apa yang Bapak/lbu berikan untuk menumbuhkan semangat belajar AL? \\
\hline 5. & Mengapa hadiah dijadikan sebagai motivasi anak? \\
\hline 6. & Apa kelebihan dan kekurangan AL dalam belajar? \\
\hline 7. & Harapan Bapak/lbu kepada AL dalam belajar ke depanya? \\
\hline
\end{tabular}

Pedoman wawancara Teman

\begin{tabular}{|l|l|}
\hline No. & \multicolumn{1}{|c|}{ Pertanyaan } \\
\hline 1. & Dapatkah kamu ceritakan karakter AL, menurut pandanganmu? \\
\hline 2. & Apakah AL termasuk siswa yang aktif dan rajin dalam belajar? \\
\hline 3. & Apa kelebihan AL dalam belajar? \\
\hline 4. & Apakah AL tidak sungkan dalam mengajarkan kamu mengenai pelajaran? \\
\hline 5. & Apa yang kamu harapkan untuk AL ke depannya. \\
\hline
\end{tabular}

